\title{
Article
}

\section{Quietude and Identity - The Silent Core of Language}

Siebers, Johan Isaac

Available at http://clok.uclan.ac.uk/3867/

Siebers, Johan Isaac (2012) Quietude and Identity - The Silent Core of Language. Empedocles European Journal for the Philosophy of Communication, 4 (1). ISSN 1757-1952

It is advisable to refer to the publisher's version if you intend to cite from the work.

For more information about UCLan's research in this area go to

http://www.uclan.ac.uk/researchgroups/ and search for < name of research Group>.

For information about Research generally at UCLan please go to http://www.uclan.ac.uk/research/

All outputs in CLoK are protected by Intellectual Property Rights law, including Copyright law. Copyright, IPR and Moral Rights for the works on this site are retained by the individual authors and/or other copyright owners. Terms and conditions for use of this material are defined in the policies page.

\section{CLoK}

Central Lancashire online Knowledge www.clok.uclan.ac.uk

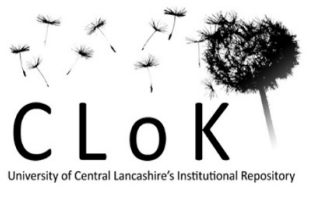




\title{
Quietude and Identity - The Silent Core of Language Johan Siebers
}

\begin{abstract}
Despite the Heideggerian advice to remain silent about silence, this article explores the idea of a fundamental silence at the core of language, an idea that is present in the phenomenological tradition from Husserl to Derrida, but also in other thinkers. The relation between silence, speech, the face and identity is charted, and related to the question what it means to speak a language, and to speak this language rather than that language. The considerations establish the need for a philosophy of communication (in addition to a science of communication) and for an ethics of cautious anticipation regarding language change and linguistic diversity, an ethics which avoids the complicit dangers of (cultural and linguistic) fetishization and instrumentalisation; a multiverse of languages emerges as the only state in which language can exist.
\end{abstract}

\section{Introduction}

In what follows, I consider the correlation between language and identity from the point of view of the speaker of a language. My concern here is primarily theoretical or interpretative: how to understand what it means to speak a language, and this language rather than that language, and what the ramifications of this understanding are for the interaction between different languages, or perhaps rather between speakers of different languages. To indicate what is at stake here proleptically: speaking is the articulation of the living present, it is life being given to itself in the moment of its occurrence - but, as will hopefully become clear - this is a complex notion.

I will presuppose the deep importance of language to human beings, as expressed in a well known remark by Wittgenstein: 'the limits of my language mean the limits of my world. ${ }^{\prime}$ How exactly to understand this statement will concern us later; here all I want to draw attention to is the fairly commonplace notion that our sense of identity, of who we are, is to a significant degree determined by the language we speak, and that different languages manifest to a certain degree different sets of (cultural) experiences and ways of interpreting the world - although these modes of interpretation are never entirely closed off to others (we are not advocating cultural relativism when we acknowledge that languages all in a different way articulate experience). When a community of speakers loses its language, by cultural, economic or military domination of another community, gradually or suddenly, by the process of extinction or by violent suppression, there is always a sense of a loss of a world. The politics of multiculturalism include the politics of linguistic diversity. Of course, a mere policy of linguistic diversity does not constitute the full acceptance of linguistic difference: diversity could very easily become merely symbolic, museum-like, if it is exercised in the context of a clearly dominant language -

\footnotetext{
${ }^{1}$ Tractatus Logico-Philosophicus, 5.6. The idea, is of course, much older and not limited to a particular philosophical tradition. Suffice it here to mention Humboldt's identification of the 'spirit' of a people with the inner form of its language.
} 
variety does not necessarily constitute diversity, a fact which applies just as much to cultural worlds as to languages. Variety can be predicated on an underlying sameness; diversity would seem to require the precarious tension of an open dialogue in the absence of a prior available codified commonality, whether this is linguistic or cultural. There is an abysmal difference between communication using a lingua franca, and communication in which direct translation into each other's language occurs.

I want, however, to approach the question from another perspective still. It seems to me that there is a need, in addition to the wide spectrum of endeavours to give objectifying explanations of the complexities involved in the relation between culture, language, cognition and the individual, to articulate the phenomenon of 'speaking-alanguage', as it were, from within, in order to understand not just how the world is present (or absent) in my language, and vice versa, but also how I am present (or absent) in my language. Only if we understand this dimension in its own terms, will we be able to gain an adequate insight into what is at stake in the general phenomenon of human communication, and in the more specific phenomenon of linguistic particularism, of that fact that we are speakers of a language.

The idea that the objective study of language and language use is possible only on the basis of a prior articulation of language and language use in experiential, or phenomenological, terms, is not new. It forms the basis of the phenomenological project that was started by Husserl over a century ago - the battle against psychologism and naturalism in the study of consciousness and existence - and is not just limited to the study of language, but stretches out to encompass the entire empirical domain:

"Thus "phenomenology" means apophainesthai ta phainomena - to let that which shows itself be seen from itself in the very way in which it shows itself from itself. ${ }^{2}$

As long as we hold on to the idea that scientific truth needs to be founded in indubitable truth, that its concepts have to derive from a source that is certain or, if we dispel with certainty and what cannot be doubted, concerns a level of presentation or manifestation at which the notions of certainty and doubt are not applicable, phenomenology is necessary in providing that foundation. The disclosing articulation of 'what shows itself form itself' precedes any other analysis.

While the project of phenomenology has been heavily criticised, and in a way brought to closure, by the critique of Derrida and others ${ }^{3}$, that critique moved and continues to move within the domain laid out originally by Husserl and which provided philosophy with a role of its own among the sciences. Both Husserl and Derrida would probably agree with Heidegger's statement that (empirical) science 'doesn't think'4; the activity of

\footnotetext{
${ }^{2}$ Heidegger, Being and Time, Oxford: Blackwell 1962, p. 58.

${ }^{3}$ D. Moran, Introduction to Phenomenology, Abingdon: Routledge 2000, pp. 435ff. It is important to note that currently there is a revival of phenomenological work, particularly in France (see e.g. M. Richir, Fragments Phénoménologiques sur le Langage, Grenoble: Millon 2005).

4 'Die Wissenschaft denkt nicht', Heidegger, Was heißt denken?, Tübingen: Max Niemeyer Verlag, 1984, p. 4.
} 
articulating the constitution of meaning, and of responding to meaning, cannot happen or be understood in terms that are abstractive of or external to that very meaning - or to put it differently, it is only from within thought that we can understand thought. The difference between Husserl, Heidegger and Derrida concerns the what and how of what shows itself, not the basic orientation of thought, the basic project or aim of philosophy, even if between each of these the concept of philosophy undergoes deep changes.

The question what it means for a speaker to speak a language has, at least also, a properly 'philosophical' dimension, one which we can only get close to by using the language of philosophy, or phenomenological description and analysis and reflective critique. An understanding that would be based on such an approach would not be incommunicable to other types of accounts, but it would have to be developed on and in its own terms nonetheless.

\section{Phenomenology of Speech}

The place of speech in phenomenology is not peripheral. Derrida argued that presence to self, which is the heart of phenomenological analysis, takes its origin from the presence to self that is given with the experience of hearing oneself speak. ${ }^{5}$ But, as Derrida showed, the analysis of the phenomenon of hearing oneself speak establishes that there is an opening, a hiatus, within it - the present is already, from the start, infected by the past and the future, by what is no longer present and what is not yet present. In the concepts of difference and deconstruction, Derrida made this realisation to the guiding motif of his philosophical writings: presence and absence (and many other opposed terms like it) are internal to each other but at the same time remain heterogeneous. ${ }^{6}$ Schiller said: "when the soul speaks, alas, the soul speaks no longer." There is an indelible gap between the self and its speech, and yet the self speaks. Whereas spoken words necessarily appear as being of perfect proximity to the speaker - I hear myself speak immediately - and as such seem to be the perfect union of the empirical, or material, and the ideal, on closer inspection (even here) there is a constitutive gap:

"Taking auto-affection as the exercise of the voice, auto-affection supposed that a pure difference comes to divide self-presence. In this pure difference is rooted the possibility of everything we think we can exclude from auto-affection: space, the outside, the world, the body, etc. As soon as it is admitted that auto-affection is the condition for self-presence, no pure transcendental reduction is possible. But it was necessary to pass through the transcendental reduction in order to grasp this difference in what is closest to it-which cannot mean grasping it in its identity, its purity, or its origin, for it has none." (Derrida, Speech and Phenomena, p. 82)

\footnotetext{
${ }^{5}$ Derrida, Speech and Phenomena and Other Essays on Husserl's Theory of Signs, Evanston: Northwestern University Press, 1973.

${ }^{6}$ I owe this fortunate formulation to Leonard Lawlor, Derrida, entry in the Stanford Encyclopedia of Philosophy, http://plato.stanford.edu/entries/derrida/\#Inc (accessed 18 December 2009). It is also a concise way of expressing what the paradoxical ground structure of human communication is: presence and absence at the same time (and what do 'same' and 'time' mean here?), the presence of absence and the absence of presence.
} 
This is not the place to consider the question whether Derrida has been correct in his critique of Husserlian phenomenology ${ }^{7}$. I take from his analysis the idea that speech is possible on the basis of a difference that is at work in the heart of the phenomenon of presence-to-self, and that consequently the self that speaks, the subject, is produced by, or always inscribed in, the movement of difference, that it is not transcendental as that to which difference happens (p. 82). The self that speaks, the living present, is a trace, constituted by the difference that makes speech possible and yet always removed from who speaks as well as from what is said:

But this pure difference, which constitutes the self-presence of the living present, introduces into self-presence from the beginning all the impurity putatively excluded from it. The living present springs forth out of its nonidentity with itself and from the possibility of a retentional trace. It is always already a trace. This trace cannot be thought out on the basis of a simple present whose life would be within itself; the self of the living present is primordially a trace. The trace is not an attribute; we cannot say that the self of the living present "primordially is" it. Being-primordial must be thought on the basis of the trace, and not the reverse. This protowriting is at work at the origin of sense. (Derrida, Speech and Phenomena, p. 85)

There is, I would like to say, a silence at the heart of the self of the living present. ${ }^{8}$ Husserl and Derrida give differing accounts of this silence - for Husserl there is a consciousness that precedes predicative articulation of its contents, and as such is silent - the prelinguistic disclosure, presence, of phenomenality in the transcendental ego; for Derrida it is only within language that the trace of what escapes language - the self of the living present - is given as being in abeyance. ${ }^{9}$

\footnotetext{
${ }^{7}$ In particular, Derrida discusses the relation between sense and temporality, and argues that the auto-affection which constitutes self presence is the temporal relation between now and its articulation, in which it becomes a trace - the spoken word is gone the moment it is spoken; it is always already 'outside of itself', 'going forth into the world', and as such at odds with the 'inwardness of speech' (p. 86). The movement of time appears as constitutive for meaning. Derrida notes that Husserl himself was aware of the fact that temporality cannot be properly named: 'every language fails to describe this pure movement other than by metaphor' (p. 84). ${ }^{8}$ Inversely, Derrida analyses the secret as requiring auto-affection: I have so say a secret to myself in order to keep it - and maybe even always to another as well - even if only as a fictitious sharing or representation. A secret must be shared. (See Derrida, "How to Avoid Speaking: Denials", in: S. Budick \& W. Iser (eds.), Languages of the Unsayable: The Play of Negativity in Literature and Literary Theory, New York: Columbia University Press, 1989, pp 3-70.)
}

${ }^{9}$ It seems to me that Merleau-Ponty follows Husserl in his account of the silence at the core of language, but he highlights the fact that meaning has to be apprehended - language, also my own, has to be heard, and as such requires a preliminary silence which is nevertheless conscious:

'[L]anguage presupposes nothing less than a consciousness of language, a silence of consciousness embracing the world of speech in which words first receive a form and a 


\section{The silent core of language}

We can see the accounts of the act of speaking that we find in phenomenology as accounts of mediation, or more precisely of the relation between the immediate and the mediated. With this opposition we enter dialectical thinking. We must realise that there is a paradoxical relationship here (see note 6). The unmediated, immediate, is as such the immanent horizon of mediation - this would, I suggest, be an alternative formulation of the idea of the trace, for what else is it than the idea of an immanent transcendence, a "transcending without transcendence"? ${ }^{10}$ As Bloch (who used the idea of the trace long before Derrida, in a similar way ${ }^{11}$ ) says, it is 'source and mouth' of the process of expression but as such remains - as yet - extraterritorial to it. ${ }^{12}$ In a real sense the core of that process is something that has not entered into its own process of expression at all, and yet that process is its eventual articulation. ${ }^{13}$ Therefore it is as much origin as total completion - it is what circumscribes the process of expression - temporality in Derrida's sense - as its principle. Is the difference that is at play here the constitutive but endlessly implicit, unlocalisable movement of meaning; that which always upsets any identity of meaning (Derrida's différance) but has no goal? That which is outside all orientation, but which also makes meaning possible by opening up a difference that makes contrast possible, and therefore thematization and signification? Or is there a way, maybe even a

meaning. This is why consciousness is never subordinated to any empirical language, why languages can be translated and learned, and finally, why language is not an attribute of external origin, in the sociologist's sense. Behind the spoken cogito, the one which is converted into discourse and into essential truth, there lies a tacit cogito, myself experienced by myself.' (Merleau-Ponty, Phenomenology of Perception, London: Routledge 1962, p. 403) The fact that languages can be translated and learned, and are, in certain aspects of their constitution, not open to 'sociology', would have to receive a different explanation in Derrida's account of speech; a beginning of an account could be found in the realisation that the movement of difference which constitutes the subject as trace, despite (or rather because of) having no identity, purity or origin, is always the same. If repetition is not possible, then precisely because of that each iteration or now becomes infected with the sameness of singularity. It remains unclear whether this would constitute a point where the Hegelian dialectic of being and nothing could be re-introduced to overtake the movement of difference, mutatis mutandis, and to constitute a sublation of the notion of the speaker, the 'one' who speaks, rather than its deconstruction, but the utopian dimension of communication that I discuss below could be taken in this way. (For a further discussion of this point, see my 'Substance as Depth', in: Zeilinger (ed.), VorSchein, Nürnberg: Antogo 2010 (forthcoming)).

${ }^{10}$ Bloch, Atheismus im Christentum, Frankfurt: Suhrkamp 1969, p. 3. My translation.

${ }^{11}$ See his Spuren (Frankfurt: Suhrkamp 1969; English Traces, Stanford: Stanford University Press, 1996).

12 'Quell und Mündung', Bloch, Das Prinzip Hoffnung, Frankfurt: Suhrkamp 1959, p. 336.

${ }^{13}$ The word 'core' has to be understood very precisely here: it should be divested of connotation of a hidden presence. Yet it cannot simply be replaced by 'margin' as its metaphysical other that is inscribed in it (Derrida). Truth is not a minted coin which can be taken in just like that (Hegel); "core" points to something that is not yet there (see the discussion below). 
necessity, to say that the trace is not so much a trace of a subjectivity or self that is already there, present but hidden and attempting to fuse with its own act of expression into the living moment of self-presence, but of a self that is not yet ${ }^{14}$, and as such, in its negativity, motivates speech, its eventual 'presence' being no more than a trace of the completion of expression, not even further analysable or imaginable (and as such acquitting those who speak in its name of the spell of 'metaphysical presence')? Is it not the case that even for Derrida the moment of that which may come to pass, the moment that should never be made impossible and which he liked to call justice, has to be seen in the light of the not-yet of the trace; of its promise, despite everything that has been said, of the 'soul' 'speaking' of an encounter? For one thing, how can the illusion of presence, the metaphysical urge, otherwise be explained ${ }^{15}$ There appears to be a prolepsis at work in our speaking of, and experience of, the self as speaking - we speak in the name of one who is not yet there. But that very structure, which we may perhaps call the proleptic structure of speech, is given. A utopian dimension, an orientation, a dimension which Bloch called hope, seems to be involved in the relation between self, expression, temporality and speech or language.

I have here merely sketched a possible path for thought which would make it possible to articulate the silence at the core of language, the silence in speech, as the location of the speaker in his or her language, and moreover of seeing that silence as, although constitutive of the speaker, a not-yet, a pre-figuring, which puts the speaker in the light of not yet being what he or she is, or could, be, as much as the language itself that he or she speaks. Both speaker and language have, in this precise sense, their utopias. In the silence of the speaker, the silence as the absence of speech (which is always the possibility of a beginning of speech) but, more strongly, also the silence that becomes visible, audible, only in speech, in that silence origin and destiny, source and mouth, of the spoken life trace themselves.

\section{The multiverse of languages}

We have now detached the idea of 'my language', as the medium for my ethno-cultural sphere of belonging, from the utopian sense of belonging in which I could become to belong to myself, my world and my language - the completion of desire for an integral restitution of self. We have also considered the idea that this desire for an integral restitution of self cannot be eliminated from an adequate philosophical account of what is involved in speaking a language, that the very act of speaking can effect many things, but that it is always also the articulation of this desire. What then is the relation between this almost existential meaning of 'speaking', which now differs remarkably little from the meaning of 'being', and the language that I speak? For phenomenology the relation is contingent, as we have seen - the silence of consciousness precedes language and makes

\footnotetext{
${ }^{14}$ The concept of the 'not-yet' as a basic category for ontology and anthropology is derived from Ernst Bloch's philosophy. See J. Siebers, 'Categorial Intelligibility', in: F. Vidal, Träume gegen Mauern, Talheim: Talheimer Verlag, 2009, pp. 83-94)

${ }^{15}$ Assuming we do not want to revert to a Heideggerian account in terms of Being arranging its own withdrawal.
} 
translation possible. Empirically there may be many regions of experience that are initially opened up or closed off for me by the language I have learnt to express myself in, and even phenomenology presupposes that I have been brought up in a community, a tradition, a language - but transcendentally the diversity of languages is of no effect. Strangely enough, perhaps, something like this could be claimed to apply to Derrida's analysis as well; the movement of difference is so omnipresent that the difference between languages and between occasions of speech lapses. ${ }^{16}$

On one hand this is a result I welcome. From a philosophical point of view it remains necessary, and perhaps today more so than before, to call attention to the danger of fetishizing languages and cultures and to point to the gap, the open space, between identity and cultural or linguistic identity. When a language or a culture is taken to have a fixed form, or even a fixed path along which it develops and changes, it can no longer be seen as the place where the openness, the trace-like nature, of human identity comes forward, and as we have seen, that openness, which is closely related to temporality itself, is the basis of meaning. We could say that tradition, and here I take a language to be a tradition of words, is only meaningful in the face of its utopia, of what it, in a radical sense, not yet is.

On the other hand, we must not lose sight of the fact that only within language the trace of the self as living presence occurs. For Derrida, the possibility of an outside, of space, the body, is inherent to the movement of difference. ${ }^{17}$ For Bloch, in a similar way, the unmediated core of mediation is only there in expression, in externalisation - the mode of inherence may be that of exterritoriality, but without the externalisation of utterance the trace, and the core, become meaningless concepts. ${ }^{18}$

My language is never simply, nor entirely, mine. Neither am I ever simply or entirely my language's. That circumstance, however, constitutes me as what I am: a trace, oriented on an identity I am not yet, in Bloch's words, a Heimat - a home. If the relapse into a reified idea of home or fatherland (or 'my language') is to be avoided, this dimension needs to be recognised as constitutive of what it means to speak a language. The forceful, or anonymised, withering away of my own language under the invasion of another's language - whether at the level of communities or individuals - can only mean that recognition is lacking, even if there can be other courses of events in which languages

\footnotetext{
${ }^{16}$ The idea that 'there is no such thing as a language, not if a language is anything like what many philosophers and linguists have supposed', was advanced by Davidson (Inquiries into Truth and Interpretation, Oxford: Oxford University Press, 2001, p. 446). The communicative exchange precedes language, as it precedes the mind and society. See E. Dresner, "Radical Interpretation, the Primacy of Communication and the Bounds of Language", in: Empedocles - European Journal for the Philosophy of Communication, 2009 (1.1.), pp. 123-134.

${ }^{17}$ As we have seen above, he calls this moment 'protowriting', the writing that is at the heart of speech.

${ }^{18}$ Bloch even relates, in a slightly more traditional language than Derrida, but to the same effect it seems, the 'breath of the spoken word' to the 'printed letter' as the only thing that 'looks after', or 'heeds' 'die Sache selber', the thing itself. (Bloch ,Tübinger Einleitung in die Philosophie, Frankfurt: Suhrkamp 1970, p. 11; my translation).
} 
disappear or change beyond recognition. The point is not historical finality, but how to deal with the diversity of languages in the time in which 'we' live. That speech is possible depends on the movement of difference, on the fact that between language and speaker the not-yet opens up; the idea of a single language lives off the premature desire to close that opening by force, in the name of perfect expressibility: like 'metaphysics', it comes too soon - not contingently, but in a radical way, by ignoring what makes itself possible in the first place. ${ }^{19}$

It seems that it could only be an attitude of caution in anticipation, of acceptance of the not-yet, that can determine our attitude towards the languages we are placed in - the other of a holy reverence on one hand, and an instrumental dismissal on the other, that a proto-ethics of linguistic diversity would seek to develop. The diversity of languages itself is of course an important indication of this caution, and it is in this light that we can say with Goethe that we would have to speak another language before we could say that we are able to understand our own, or what our own language (and our own speaking) drives at - Heimat as used above. The term 'multiverse', which we find in the works of Bloch, could be used to indicate the relation between languages. From the point of view of the linguistic utopia, that which remains exterritorial to the life of a language, the utopian direction appears as an invariant - it is always the same - but from the point of view of the individual languages it appears as radial difference or multitude. A multiverse, in which the multitude is turned-towards (vertere) the invariant of direction, which, however, is not available for articulation.

\section{The silence of the face}

'In the silence of the face, man is truly at home', Agamben writes. 'Unspoken words and intentions that have remained unfulfilled' leave their mark on our expression, the 'character' of our faces, but the beauty of the face is the silence of language itself, the 'becoming visible of the word', the 'idea of language' 20 - and as such an index of identity as home, Heimat. It is evident that the analysis of the face can proceed along the same lines as the analysis of the word - from the 'metaphyiscal' idea that there is a presence which decides to articulate itself, and thinks it finds that it can achieve both visibility and ideality - externality and presence-to-self - in the face (as in the spoken word), we can move to the insight that it is the movement of difference which makes the face possible, as itself only there in a movement which cannot be fixed and which constitutes the one whose face it is as a trace in, gliding over, the movements of the face. The face is not simply a medium, as a letter or other message might be, but it also is not simply the person. The person is

\footnotetext{
${ }^{19}$ Perhaps this ignoring of what really matters, if I may put it like this, is a necessity, or at least almost unavoidable, and the point of philosophy is to show us the way through it, rather than around it.

${ }^{20}$ G. Agamben, Idea of Prose, Albany: State University of New York Press, 1985, p. 113.
} 
exterritorial to the face, and yet I see him or her when I look at his or her face; the face is his or hers. ${ }^{21}$

The phenomenological analysis and its deconstruction have deliberately ignored the communicative dimension of language and expression, as can be seen from various remarks in the works of Husserl as well as Derrida. ${ }^{22}$ The point about the self as living presence for Husserl is precisely that communication, Kundgabe, is not necessary for it when I speak to myself, I am not informing myself about something. Auto-affection involves a hearing to be sure, but it is a hearing of myself by myself. For Derrida the common conception of communication as a sharing of meaning would be problematic, because the movement of difference will always inscribe an impurity in the very act of affection, whether it be affection of other or self. For him, in a way, the whole point of difference is to deconstruct the idea of communication.

And yet, in the face perhaps even more than in the spoken word, I behold, encounter, another - not a sight or a sound on the basis of which I conclude to the existence of a hidden but real other self, but someone, someone for whom a world exists, for whom others exist. In the silent face I can even encounter the whole spectrum of the not-yet in language and self that I discussed earlier.

The face is unique. It seems to differ from the spoken word in that the word is essentially a presence to self - I hear myself speaking in the same instance as I speak whereas I do not see my face in the same instance as I express myself. My face relegates me to the passivity of being seen by others; even if I can feel the movements of my facial muscles when I laugh or frown, my face remains hidden from me. The indelible difference to self becomes especially apparent when I look at myself in the mirror. I meet someone face-to-face; the face is that by which we can come to stand over against each other, but I cannot come to stand over against myself in that way. The face is more radically an outside, a spatialisation, then the word - more radically an impurity in the presence-toself that now more radically even than before appears as a trace or a not-yet. ${ }^{23}$ It is now mediated essentially by the other whom I encounter 'face to face'. Only in the phenomenon of face to face communication, the full paradox in the relation between speaker and language becomes apparent, the full implication of me in my speaking, the full extent to which ' $\mathrm{I}$ ' is a movement outside of oneself and a not-yet having returned, via another. As Ernst Bloch put it: 'Ich bin. Aber ich habe mich nicht. Darum werden wir erst.' (I

\footnotetext{
${ }^{21}$ And what is said of the face here, can be extended to the body, not as a material corpus but as my body - I do not have a body, I am my body - and yet not simply. The utopian dimension of the face would take us into (a reinterpretation of) religious domains: 1 Cor. 13: 'for now we see through a glass darkly, but then face to face'. In addition, the face and the body, just like language, require themselves a context of care: our relation to them is not only passive but also active.

${ }^{22}$ An exception would be Merleau-Ponty's chapter on the body as expression and speech (in Merleau-Ponty, Phenomenology of Perception, 164-199); an analysis of this text must be left out of the present study, unfortunately.

${ }^{23}$ There is no cognitive, evidential, value as such in linguistic usage, but do we not say that something 'is written all over someone's face'?
} 
am. But I do not have myself. Therefore we are yet becoming. $)^{24}$ With the aspect of the face we can account for the communicative dimension of speech and meaning; language remains unthinkable without the spoken word that crosses over between faces, that is spoken through a face (per-sonans) to a face. The 'idea of language', as Agamben says, becomes visible in the silence of the face.

\section{From Philosophy of Language to Language Politics}

In the foregoing analysis allowed myself some rhetorical licence in tyring to articulate what I think are essential correlations and aspects of the speaker-speech-language complex. A failure to recognise at least the area which I have tried to indicate seems to me to have potentially damaging consequences not just for a theory of communication, but also for the practical (ethical and political) aspects of language policy and the education of articulate citizens. In order to achieve this aim, I have developed the beginnings of an account of what can only be called a Blochian or utopian philosophy of communication the utopia of expression I have hinted at should however not be taken to imply a pragmatic programme of action by which to achieve an abstract present perfect that is, somehow, somewhere, already waiting for us. Rather, the communicative utopia has to be seen as concrete, not abstract - a motif in understanding the orientation that is to be found within speech, and only in the name of which the idea of expression as someone expressing himself or herself regarding something can be meaningful. The burden of proof regarding the relation between the trace of Derrida and the not-yet of Bloch has not been lifted entirely here, but merely indicated. The difference is crucial, though; it is the difference between the invariant of direction that is exterritorial to history but as such implied in it, and the endless sameness of difference. In the play between these two concepts, we can attempt to retrieve an understanding of truth, of encounter and of cultural progress (all of which must be left to another occasion here), and in the wake of that attempt, perhaps come to understand these somewhat obscure but nevertheless, as I hope to have shown, essential aspects of the human being as 'the one who speaks his language'.

The analysis has also indicated a road along which the concept of dialogue, of face-toface conversation, can be explored in dimensions that perhaps up until now have not received enough attention. The full externalisation that we uncovered in the concept of the face turns out to be essential for speech. ${ }^{25}$

I started by quoting Wittgenstein, 'the limits of my language mean the limits of my world.' I used this quotation in a merely suggestive way, and have not occupied myself with an exegesis of its meaning. Yet, the threat of 'relativism' appears in my analysis as unfounded; the silence in language is the not-yet of the universality of reason. It provides

\footnotetext{
${ }^{24}$ Bloch, Spuren, p. 1. My translation.

25 The application the category of 'face' has found in pragmatics, on the basis of the sociology of Goffman, can be seen as a codified cognate of face as it is described here; the gap between the two, however, is deep. This would be good example of an aspect of language that is not open to sociology, as I indicated above.
} 
the antidote to relativism, even if, or rather because, it is the opposite of an available, positive, universal. In that silence we encounter also ourselves as yet to become who we are - and this applies not just to the individual speaker of a language, but to a language community as a whole. In the light of the silence of the universal, which as I hope I have shown is not a mere absence or negation of the universal but a not-yet given with language, we can modify or understanding of 'identity' as something that is also a becoming, a process, rather than a state. The idea of identity is closely connected to the idea of the true language. We can understand why by considering that language is the medium by which we connect outer and inner experience. Perhaps the idea of a perfect language, which has been a constant in Judeo-European culture from the idea of the adamite tongue to the logicists' idea of a perfectly transparent and unambiguous language of thought, goes astray when it is conceived of as something that is at our disposal, that we have or can create a language with which to name all things. Such a language would not be the language of human communication - it would be a regimented tool to coordinate behaviour, but not the living word of the human encounter. The unification of the human encounter and the language in which to name all things, the dream of reason we could perhaps say, has to be conceived of as a not-yet, a perspective in the light of which present actuality can be measured and sometimes judged - a hope, regulative idea or counterfactual presupposition. ${ }^{26}$

Language violence, when it takes the form of discriminating against a group of people on account of the language that they speak, or prohibiting them from speaking and developing their language, is a gesture that lives off the denial of the proleptic nature of the universal: it mis-takes the premonition of identity, or 'home', that is given with the strong experience of being at home in one's language for the admonition to incarcerate identity in one's present language. What would be required, on the other hand, would be an attitude that recognises that there is no easy way of transcending one's language - for example in a constructed universal lingua franca - and yet we are never already or fully at home in our language. The ontological constitution of language is such that we can only speak of 'languages' - a pluralism is given with the fact that the words I speak are never simply my own. In that respect there is little difference between the level of the individual speaker, who uses words that have first been spoken to her, and the level of what we call the different languages. From the point of view of the speaker, Parole (or Bakhtinian discourse) appears to have priority over langue, and parole is the world of the spoken and repeated word, open to drift and difference. Our analysis of the relation between speech, the face, the word and silence has enabled us to draw this conclusion. The analysis can be made fruitful for the political theory of language if we see that what is here said about identity constitutes an addition to the discourse of power that has been developed in political linguistics. Whereas it has been a structural feature of much political linguistics to treat identities as given and as entwined in politicised struggles for hegemony, our

\footnotetext{
${ }^{26}$ There are obvious parallels to be drawn here to Habermas' idea of the ideal speech situation, as well as to Badiou's notion of evil as 'the desire to name at any price'. See my 'What Cannot be Said: Speech and Violence', Journal of Global Ethics (7.2), 2010, forthcoming. I prefer the language of hope to that of the regulative idea or counterfactual presupposition, for reasons given above.
} 
analysis highlight features of the idea of identity which are the opposite of power; no discourse of power can articulate what is at stake in the notion of the silence of the face, yet that is what underpins the notion of identity. While I do not dispute that we need recourse to a discourse of power when we investigate the relations between language communities, it does appear to be the case that the exclusivity of the discourse of power in this context is itself an example of not adequately acknowledging the proleptic nature of language and identity. ${ }^{27}$ Moreover, an ethics of linguistics pluralism cannot be based solely on an emancipatory discourse which ends with a truce between or at best a coexistence of, linguistic communities: no one owns their identity enough to stand such a situation, thus always spawning new incarnations of imperialism. Language is intrinsically pluriform, my language and the language of my community is always already permeated by the language of another and by another language - the space of language - both the linguistic space and the space in which a language is materially present - is necessarily open; attitudes of forced linguistic preservation, linguistic ethnocentrism and bland imperialistic cosmopolitanism destroy the living space of language. The politics of language has to be based on the ethics of language. The ethics of language has to be based on an ontological understanding of the nature of the human communicative encounter.

Linguistic imperialism, such as described in various places in this book, is, in terms of the foregoing account, not simply the silencing of one language by another, but a 'silencing of silence' which affects all who share the space of language. While the immediate causes or goals of linguistic imperialism will often be found in certain economic, political or cultural interests, and the immediate effects of it will make themselves felt in clearly visible economic, political and cultural exclusion, the deep effects (and indeed efficacy) of linguistic discrimination can only be adequately explained if we take into consideration the vulnerable but essential dynamics that lay at the heart of the act of speaking. The consolation I have offered, that in the act of linguistic oppression, the majority language loses itself, its voice, just as much as the minority language, may seem far-fetched and, in the light of these direct effects, not of much significance. But philosophy of language, and indeed linguistics, cannot stop imperialism or the deadening of languages by museal preservation and ethnocentrism .They may, however, help us understand better what is at stake in formulating and enacting a politics of language that aims to make space for all. It goes without saying that in an age of continuing globalisation the question of language and identity will have to be asked over and over again, and will determine significantly social developments in the years to come. We blind ourselves to its ramifications if we ignore the existential dimensions of it.

\footnotetext{
${ }^{27}$ It would take us too far out of the context of the present paper to investigate the propensity to this mistake, which I think is given with the utopian ontological structure of identity. I refer here to Kenneth Burke's sadly somewhat neglected suggestion that the drift towards identification and perfection is intrinsic to language use and to meaning and has to be understood as transcendence, which would enable us to articulate these connections in more depth. See Burke, The Rhetoric of Religion: Studies in Logology, Berkeley : University of California Press, 1970.
} 